\title{
Estimating adult mortality in Zambia using information on survival of parents from surveys
}

\author{
Vesper H. Chisumpa \\ University of Zambia, Department of Population Studies \\ P.O. Box 32379, Lusaka, Zambia \\ vchisumpa@zambia.co.zm \\ Rob Dorrington \\ Centre for Actuarial Research, University of Cape Town \\ Private Bag X1, Rondebosch 7701, South Africa
}

\section{Abstract}

The aim of this study is to derive estimates of level of and trend in adult mortality in Zambia. To do this the study applies the standard orphanhood method to the data on survivorship of parents from various Zambia Demographic and Health and Living Conditions Monitoring Surveys to estimate ${ }_{10} q_{25}$ and ${ }_{15} q_{25}$ for females; and ${ }_{10} 9_{35}$ for males, and hence, the probability of a 15 year old dying before age $60\left({ }_{45} q_{15}\right)$. The study finds that the orphanhood method captures some of the trend but fails to provide definitive estimates of mortality. The levels of female adult mortality between ages 25 and 35 years have remained constant at about 15 per cent from the mid-1990s. The female mortality rate between ages 25 and 40 years has also remained constant, at between 20 per cent and 25 per cent since 2000. Adult male mortality between ages 35 and 45 years increased in the mid-1990s and has remained between 20 per cent and 25 per cent from the late 1990s to late 2000s. Adult mortality, ${ }_{45} 9_{15}$, for both males and females, has increased over time and has stabilised at about 60 per cent for males and 50 per cent for females. These adult mortality rates are comparable to estimates from other sources.

Key Words: Adult mortality, estimation, orphanhood, Zambia

\section{Introduction}

The lack of accurate estimates and methods for ascertaining adult mortality, compared to those of child mortality, is a major concern (United Nations 2006). This is particularly so for developing countries that do not have data collection systems that capture vital events on a reliable and continuous basis.

The advent of the Human Immunodeficiency Virus (HIV) and Acquired
Immunodeficiency Syndrome (AIDS) epidemic has increased the demand for adult mortality estimates to monitor and determine its impact on mortality. Zambia is one of the countries in subSaharan Africa most affected by the AIDS epidemic, with prevalence above that for Africa (Macro International Inc. 2009). The 2004 antenatal clinic surveillance survey estimated that 19 per cent of pregnant women attending antenatal clinics were HIV positive (Ministry of Health and Central Board of Health 
2005). The 200I/2002 Zambia Demographic and Health Survey (ZDHS) estimated that 15.6 per cent of Zambians aged between 15 and 49 years are infected with the virus (Central Statistical Office, Central Board of Health and ORC Macro 2003). However, the 200 ZDHS reported a statistically insignificant decline in HIV prevalence to 14.3 per cent (Central Statistical Office, Ministry of Health, Tropical Diseases Research Centre et al., 2009).

In spite of the high HIV and AIDS prevalence in the country, not much attention has been paid to estimating the levels and trends in adult mortality in Zambia. Adult mortality estimates obtained from the ZDHS surveys reports show that adult mortality has increased. Adult mortality rates for persons in the age group 15-49 years increased from 10.9 deaths per 1,000 person-years of exposure for the period 0-6 years before the 1996 ZDHS to I4.I deaths per I,000 personyears of exposure for the period 0-6 years before the 200I/2002 ZDHS and marginally declined to 12.5 deaths per I,000 person-years of exposure for the period 0-6 years before the 200 ZDHS (Central Statistical Office, Ministry of Health, Tropical Diseases Research Centre et al., 2009). Thus, between the 1996 ZDHS and 200I/ 2002 ZDHS adult mortality rates increased by 29 per cent and then declined by II per cent between the 2001/2002 ZDHS and 200 ZDHS, with a notable decline observed in male mortality. However, despite this recent decline in mortality rates, adult mortality in Zambia remains high by African standards. A probable reason for the increase in adult mortality in Zambia is the HIV and AIDS epidemic.

Accurate data on adult mortality from the vital registration system are not available for Zambia because registration is incomplete. Consequently, the only other available sources of mortality data are censuses and surveys. These sources provide information that can be used with indirect methods to estimate adult mortality in Zambia.

This study uses the standard orphanhood method based on the survival of parents (Brass and Hill 19 $\square 3$; Blacker 19प; Timaeus 1992; United Nations 2002) corrected for the impact of HIV on the method (Timaeus and Nunn 1997) to derive estimates of level of and trend of adult mortality in Zambia.

\subsection{Significance of the study}

In a country with a high HIV and AIDS prevalence, like Zambia, estimates of adult mortality are relevant in providing a better understanding of the mortality situation for planning, decision-making and implementation of health programmes as well as other developmental programmes. The HIV and AIDS epidemic mainly affects the age group of 15 to 49 years. The impact of the epidemic on this age group has far reaching implications which affect all areas of human endeavour and have the capacity to reverse any gains in development. For instance, studies show that adult mortality poses a threat to the survival and welfare of children in households that experience adult deaths (Ainsworth, Beegle and Koda 2005; Chapoto and Jayne 2005; Noumbissi, Bawah and Zuberi 2005). Other studies have shown declines in national Gross Domestic Product (GDP), agricultural production, human resource 
loss, and decline in education standards associated with HIV and AIDS (Baggaley, Godfrey-Faussett, Msiska et al., 1994; Population Council 1998; Ainsworth, Beegle and Koda 2005; UNAIDS/WHO 2009).

In Zambia, the 2001/2002 ZDHS and $200 \square$ ZDHS data have not been utilised to estimate adult mortality using the orphanhood method. Furthermore, the Living Conditions Monitoring Survey data has to the best of our knowledge never been used to estimate adult mortality in Zambia.

\section{Data source}

To derive adult mortality estimates using the orphanhood method, data on the survivorship of parents collected by the 1992, 1996, 2001/2 and 200 ZDHS surveys (Central Statistical Office, Central Board of Health and ORC Macro 199], 2003; Central Statistical Office, Ministry of Health, Tropical Diseases Research Centre et al,. 2009) and the 1996, 1998, 2002/3, 2004 and 2006 LCMS surveys (Central Statistical Office and World Bank Unpublished) are used.

For the ZDHS surveys, information on the survival status of parents of persons under the age of 15 years in a household was collected by asking whether the biological mother or father of the person was alive or not. The age range was extended to 18 in the most recent DHS survey. The DHS surveys also provide information on births in the last year (I 2 months).

For the LCMS surveys, information on the survival status of parents was asked of members of households aged 20 years and less. The LCMS survey is a nationwide survey targeted at house- holds with the main objective of monitoring the impact of government policies and programmes on the welfare of population. The survey interviews between 9,000 to nearly 20,000 households in selected Standard Enumerations Areas (SEAs) from Census Supervisory Areas (CSAs) country wide. The survey is designed to provide reliable estimates at national, urban, rural, provincial, and district levels. The survey sample is not self-weighting, sample weights were provided to correct for the differential representation of the sample at national and subnational levels.

With respect to data quality, orphanhood data for young respondents are affected by the "adoption effect" where respondents mistakenly report on the survival status of the adopted parents rather than that of biological parents resulting in too few respondents reporting their parents to be dead (Brass and Hill 19】3; Timaeus 1991; Feeney 200I; Hill 200I; Preston, Heuveline and Guillot 200I; Bradshaw and Timaeus 2006; Dorrington, Timaeus and Gregson 200 $\square$. An assessment of orphanhood data for both the ZDHS surveys and LCMS surveys indicates that the proportion of respondents reporting that their biological mother is alive is over 90 per cent while that for biological fathers being alive is less than 90 per cent. The survival status of biological mothers is more likely to be known than that of biological fathers because mothers are more likely to be staying with the children than fathers. The proportion of respondents who did not know the survival status of their parents is, however, not significant (Chisumpa 20I0). 
2.1 Method

Using the standard orphanhood method by Timaeus (1992) with orphanhood data from the ZDHS surveys and LCMS surveys, adult mortality rates for both males and females are estimated. For females, the conditional probability of a 25 year old woman surviving to age 35 , and of a 25 year old woman surviving to age 40 years are translated into the probability of a 25 year old woman dying before reaching age $35\left({ }_{109} 9_{25}\right)$, and the probability of a 25 year old woman dying before reaching age $40,\left({ }_{15} q_{25}\right)$. For males, only one estimate is derived from ZDHS survey orphanhood data, the probability of a 35 year old man dying before reaching age $45,(10935)$. From the LCMS data, three adult mortality rates are obtained for females $\left({ }_{10} q_{25},{ }_{15} q_{25}\right.$, and $\left.{ }_{20} q_{25}\right)$ while for males, two adult mortality rates are estimated $\left({ }_{10} q_{35}\right.$ and $\left.{ }_{15} q_{35}\right)$. To facilitate comparison of the mortality rates derived from the orphanhood data of the ZDHS surveys and LCMS surveys, only the two female adult mortality rates, ${ }_{10} q_{25}$ and ${ }_{15} q_{25}$, and one male adult mortality rate, 10935 , are compared. In addition, the commonly used measure of adult mortality, ${ }_{45} q_{15}$, is also computed for both males and females. This measure is obtained from a model life table by first determining the mortality level implied by the orphanhood adult mortality estimate and then computing the ${ }_{45} q_{15}$ value at this mortality level.

In populations that are significantly affected by the AIDS epidemic, such as the Zambian population, there is HIVrelated bias introduced in orphanhood adult mortality estimates. Timaeus and Nunn (199】) show that the relationship between the survival of mothers and vertical transmission of HIV from mother-to-child biases the orphanhood adult survival estimates upwards if not adjusted for. There is higher mortality of HIV infected mothers and so is the mortality of their children, such that there are fewer children to report on dead mothers. A formula has been proposed by Timaeus and Nunn (199 $\square$ ) for calculating an adjustment to the reported proportions of mothers alive to correct for this bias.

Another bias that the AIDS epidemic introduces in orphanhood adult mortality estimates is in the use of regression coefficients to convert proportions with mothers or fathers alive to life table conditional probabilities of surviving from age 25 for women and age 35 for men. The regression coefficients used with the standard orphanhood method by Timaeus (1992) tend to overestimate the converted life table conditional survival probabilities in an AIDS epidemic because they were derived from simulations not affected by the AIDS epidemic, therefore, the unusual age patterns of mortality resulting from the impact of the epidemic are not taken into account. In addition, the use of the mean age of childbearing in the standard orphanhood method is meant to account for differences in ages of mothers over the period of exposure to the risk of dying. However, these ages are impacted on by heavy AIDS mortality. This problem of regression coefficients overestimating life table survivorship mainly affects the survival of parents of children aged below 25 years. Timaeus and Nunn (199】) have proposed provisional revised regression coefficients to 
be used with the standard orphanhood method in populations affected by the AIDS epidemic.

Orphanhood adult mortality estimates are derived by applying the standard orphanhood method (Timaeus 1992). HIV-related biases have been adjusted for by applying correction factors proposed by Timaeus and Nunn (199प). United Nations Joint Programme on HIV and AIDS (UNAIDS) estimated adult HIV prevalence rates for females aged 15 to 49 years for Zambia are employed (UNAIDS/WHO 2009) in the adjustment of HIV-related biases. To account for distortions in the age pattern of mortality due to the AIDS epidemic, regression coefficients by Timaeus and Nunn (199 $\square$ ) are utilised. However, for paternal survivorship estimates, Timaeus' unpublished regression coefficients' ${ }^{\prime}$ for age group 5-9 years are used while for the other age groups Timaeus (1992) regression coefficients are applied. Timaeus and Jasseh (2004) adult mortality rates estimated by using the 1992 and 1996 ZDHS orphanhood data were reproduced to serve as the base from which to derive mortality estimates using orphanhood data from the 200I/2 and $200 \square$ ZDHS surveys as well as the 1996, 1998, 2002/3, 2004 and 2006 LCMS surveys.

Since the Zambian population is heavily impacted by the AIDS epidemic in the 20-59 age range, a standard model life table that accounts for AIDS in translating conditional survival probabilities into common mortality indices is needed. The commonly available model life tables such as the Brass General Standard model life table (Brass, Coale, Demeny et al., 1968) and Princeton model life tables (Coale, Demeny and Vaughan 1983) do not account for the AIDS epidemic.

A unique feature of the application of the orphanhood method in this research is the use of the population and deaths by age and sex obtained from the United Nations Population Division (UNPD) population estimates and projections data for the years 1950 to 2010 that incorporate the AIDS epidemic for Zambia (United Nations Department of Economic and Social Affairs Population Division 2009) to produce standard model life tables that incorporate the AIDS epidemic at the time reference of the rates. Brass logit transformation relation (Brass, Coale, Demeny et al., 1968) with beta set to I was used to estimate alpha corresponding to each estimated conditional survival probability from the orphanhood method, which in turn was used to generate common adult mortality indices. The details of the methodological procedure of deriving the standard model life tables is elaborated elsewhere (Chisumpa 2010).

Adult mortality rates are also computed using pairs of surveys by applying the synthetic cohort procedure developed by Zlotnik and Hill (198I), which reflect mortality levels between surveys.

\section{Results}

Estimates derived from data based on the age group 5-9 represent adult mor-

I. Timaeus' unpublished regression coefficients: $\mathrm{a}_{0}=-0.55 \square 8, \mathrm{a}_{1}=0.0004, \mathrm{a}_{2}=1.4 \square 08$,

$$
\mathrm{a}_{3}=0.0695
$$


tality in the previous 10 years and less, while estimates based on age group 10 - 14 represent the mortality for the period 15 years and less. These estimates reflect adult mortality for younger parents, that is, females in their late twenties and early thirties and males in their late thirties and early forties. To establish the levels of adult mortality, conditional survival probabilities derived for both males and females have been translated into common mortality indices, and trends are approximated from their time reference points.

Figures I to 5 below present the levels of and trends in female and male adult mortality rates estimated from orphanhood data obtained from the 1992-200 ZDHS and 1996-2006 LCMS surveys using the standard orphanhood method with adjustments for HIV-related biases. Synthetic cohort estimates reflect the level of adult mortality between the dates of the two surveys.

Figure I examines the levels and trends of probabilities of a 25 year old female dying before reaching age 35 derived from the ZDHS and LCMS surveys. The ${ }_{10} 9_{25}$ was low in the 1980s at about 5 per cent, this increased gradually in the late 1990s and early 2000s, and appears to have stabilised at a level of about 15 per cent since then. In the 1980s, the UNPD estimate derived from life tables based on UNPD population estimates and projections was about 6 per cent which increased to about 13 per cent by the early 1990s, then 20 per cent in the mid 1990s and continued to above 20 per cent in the early 2000s before declining to about 16 per cent in the late 2000 s. The study estimates are lower than UNPD estimates between the mid-1990s and mid2000s, particularly for the synthetic cohort method. However, the trend over time is broadly similar. Generally, the estimates of mortality rates from both the ZDHS and LCMS surveys indicate the same pattern of levels and trends in adult mortality. The LCMS survey mortality estimates are, however, less internally consistent than the ZDHS survey estimates. Adult female mortality estimated using two surveys in combination also indicates that ${ }_{109} 9$ has remained constant at about 15 per cent to 20 per cent since the late 1990s.

Figure 2 shows that the probability of a 35 year old person dying before reaching age 45 for males has increased over the years. The probability of dying increased from about 10 per cent in the late 1980s to about 25 per cent in the mid-1990s to early 2000s. Male adult mortality increased more than female adult mortality. These estimates are close to the UNPD estimates from the mid-1980s to the late 1990s, and later for the synthetic cohort estimates. The UNPD estimate of ${ }_{10} 9_{35}$ is about 8 per cent for late 1980s and this increased to about 23 per cent in the mid-1990s. The study estimates are lower than UNPD estimates in the early 2000s period. The figure also indicates that the two-survey ${ }_{10} 935$ for males has stabilised at between 20 per cent and 25 per cent from the late 1990s. The 200I/2 \& 200 $\square$ ZDHS and 2004 \& 2006 LCMS two-survey periods produce male adult mortality rates that are consistent to each other between ages 35 and 45 years. The study estimates are similar to the UNPD estimates only in the late 2000s. 

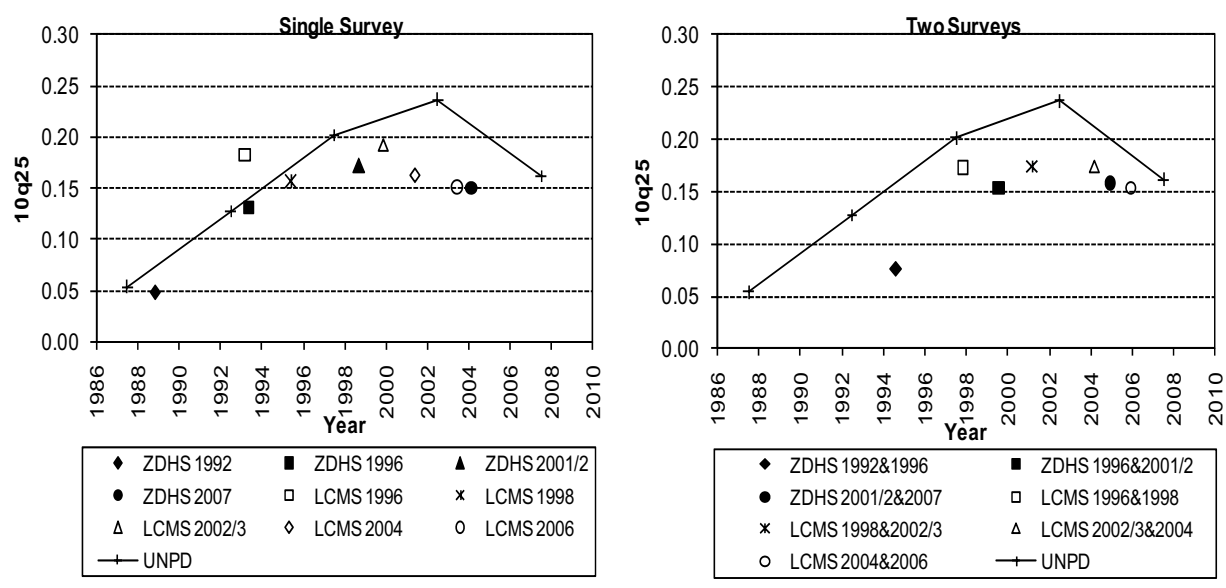

Figure I Female mortality, $\left(10 q_{25}\right)$
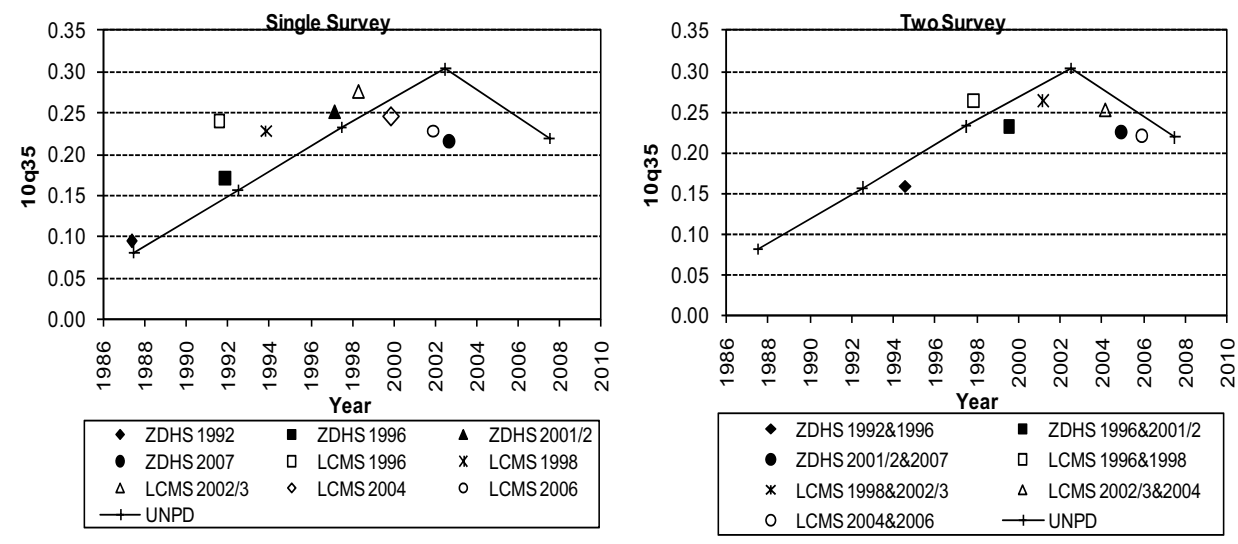

Figure 2 Male mortality, (10935)

Adult mortality rates that are lower than UNPD estimates may be attributed to the adoption effect or UNPD estimates may be too high.

Figure 3 shows that the probability of a 25 year old woman dying before reaching age 40 for females was low in the late 1980s at about 6 per cent and increased gradually from the 1990s and appears to have remained constant at between 20 per cent and 25 per cent since the mid-1990s. The two-survey estimates reinforce the point that ${ }_{15} q_{25}$

has stabilised at between 20 per cent and 25 per cent since 2000 .

These estimates are lower than those derived from the UNPD life tables. A possible reason again may be the adoption effect. The UNPD estimate of ${ }_{15} q_{25}$ is about 9 per cent for the late 1980s which increased to about 28 per cent in the mid-1990s. The 1996 LCMS survey and 1996 ZDHS survey probabilities are consistent with each other. 

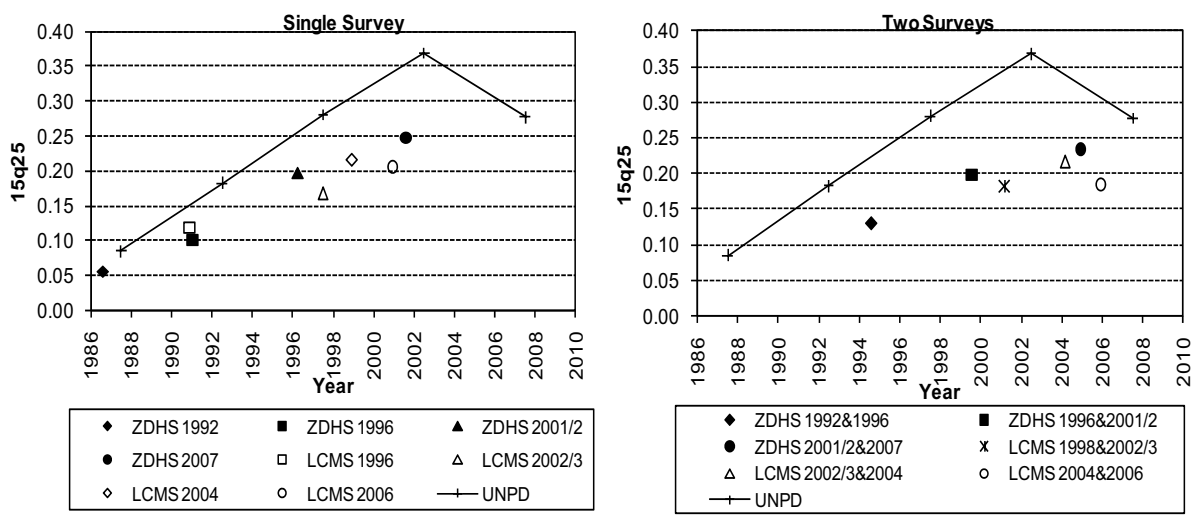

Figure 3 Female mortality, $\left({ }_{15} q_{25}\right)$

Adult female mortality, ${ }_{45} q_{15}$, has increased over time as shown in Figure 4 , it started to increase from about 21 per cent in the mid-1980s to about 29 per cent in the late 1980s. These estimates are lower than those derived from UNPD life tables, which estimate ${ }_{45} q_{15}$ to be above 30 per cent in the late

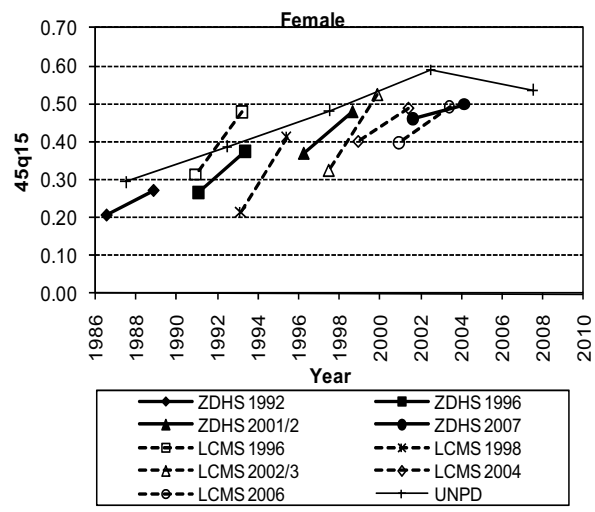

1980s. The LCMS surveys mortality estimates though less internally consistent are in agreement with ZDHS surveys mortality estimates, indicating ${ }_{45} q_{15}$ has increased in Zambia. The adult female mortality rate, ${ }_{45} q_{15}$, has remained at about 50 per cent since the year 2000.

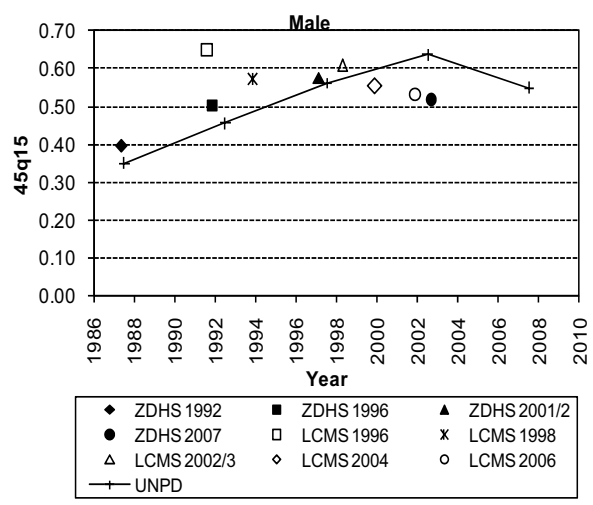

Figure 4 Adult mortality, $\left({ }_{45} q_{15}\right)$, single surveys 
Males experience higher adult mortality rates, ${ }_{45} q_{15}$, than females as indicated in Figure 4. The probability of dying started to increase from about 40 per cent in the late 1980s to about 50 per cent in the early 1990s. From the mid1990 s, ${ }_{45} q_{15}$ varies between 50 per cent and slightly above 60 per cent. These estimates approximate those derived from UNPD life tables from the 1980s to late 1990s. The estimates from the

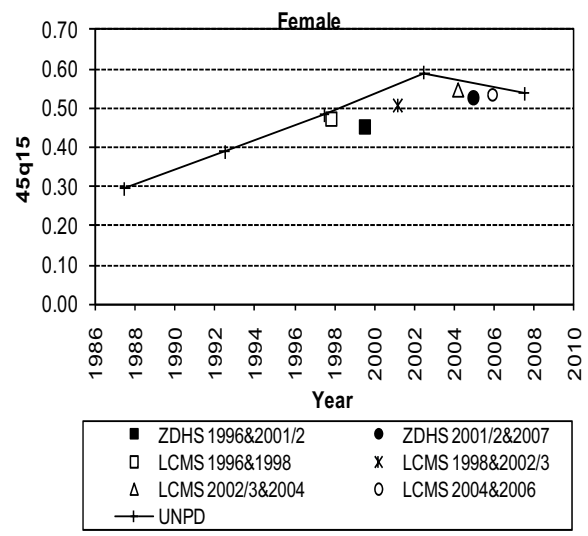

LCMS and ZDHS surveys portray the same picture of adult mortality, though mortality estimates from the LCMS surveys are less internally consistent. The 2006 LCMS and 200 ZDHS surveys adult mortality estimates are consistent with each other. Again, the 1996 LCMS survey mortality estimate is the outlier. Figure 5 shows the two-survey adult mortality estimates for females and males, respectively.

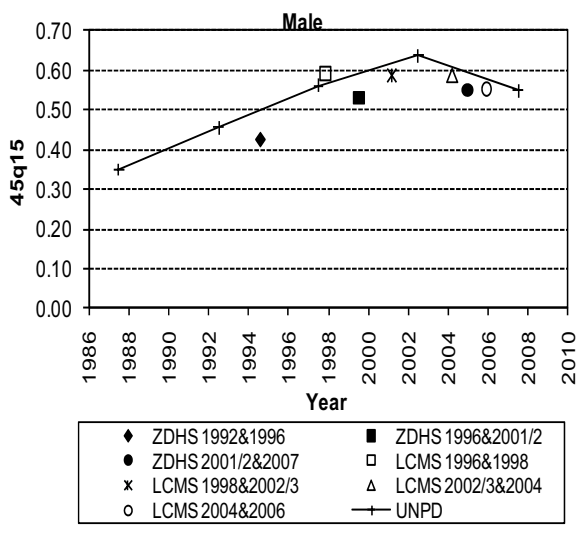

Figure 5 Adult mortality, $\left({ }_{45} q_{15}\right)$, synthetic cohorts

Figure 5 indicates that female adult mortality estimated from two surveys combined has remained constant at around 50 per cent from 200I to 2005 . The 1998 \& 2002/3 LCMS, 2002/3 \& 2004 LCMS, 2004 \& 2006 LCMS and 2001/2 \& 200! ZDHS two-survey female mortality estimates are consistent with each other. The adult male ${ }_{45} q_{15}$ has also remained between 50 per cent and 60 per cent from about 199 to 2005 . The 2004 \& 2006 LCMS and $2001 / 2$ \& 200 ZDHS two survey male mortality estimates are consistent with each other. The adult mortality estimates from combining surveys are slightly lower than UNPD estimates.

It can be noted broadly that estimates of male mortality are closer to or above the UNPD estimates while estimates of female mortality are generally lower because of adoption effect. This is because of some absent fathers, presumed dead, counter balancing the bias due to the adoption effect.

\section{Discussion and conclusions}

Overall, the study has estimated the approximate levels and trends of adult mortality rates from the data on orphanhood from the LCMS and ZDHS surveys by making adjustments to 
remove the HIV-related bias and using revised regression coefficients that account for the AIDS epidemic in affected populations. The estimates indicate that the level of female adult mortality between ages 25 and 35 years has remained constant at about 15 per cent from the mid-1990s. The female mortality rate between ages 25 and 40 years has also remained constant at between 20 per cent and 25 per cent since 2000. Adult male mortality between ages 35 and 45 years has increased over time and has remained between 20 per cent and 25 per cent from the late 1990s to late 2000s. The probability of a 15 year old person dying before reaching age 60 for both males and females has increased over time and has stabilised at about 60 per cent for males and 50 per cent for females. World Health Organization (2009) estimates also indicate that adult mortality has increased over time, the adult mortality rate, ${ }_{45} q_{15}$, for females was estimated as 29 per cent, 60 per cent and 53 per cent, and for males as $3 \square$ per cent, 68 per cent and 58 per cent for the years 1990, 2000 and 200 respectively. Given the uncertainty around adult mortality estimates, World Health Organization estimates and the study estimates may be considered to be similar in the late 2000 s. Obermeyer, Rajaratnam, Park et al., also show that adult mortality increased over time. They applied logistic regression analysis to DHS sibling history data and estimated that the adult mortality rate, ${ }_{45} q_{15}$, for females was 38 per cent in 1984 and 61 per cent in 2004 while for males it was 45 per cent in 1984 and $\square 4$ per cent in 2004. These estimates are not only higher than the estimates produced from the orphanhood data but are higher than those of the UNPD and the WHO. The study estimates are lower than those reported by Bradshaw and Timaeus (2006) and Ngom and Clark (2003) for Zambian adult females and males as 69 per cent and $\square 3$ per cent, respectively.

Adult mortality estimates derived from both the LCMS and ZDHS surveys show the same pattern of adult mortality in Zambia, although, LCMS mortality estimates are less internally consistent. One possible reason could be attributed to the quality of data on orphanhood from LCMS surveys was not as good as that from ZDHS surveys.

The study used the UNPD life tables as standard for converting conditional survival probabilities into a common index of adult mortality with the orphanhood method instead of the commonly available model life tables such as the Brass General Standard (Brass, Coale, Demeny et al., 1968) or Princeton model life tables (Coale, Demeny and Vaughan 1983). The reason for doing this is that the commonly available model life tables do not incorporate HIV and AIDS making them inappropriate for use in populations affected by the AIDS epidemic like Zambia. Period standard life tables for Zambia that account for the HIV and AIDS epidemic using UNPD population estimates and projections data incorporating the AIDS epidemic were derived, and used them to translate estimated conditional survival probabilities into common mortality indices. It should be noted that the use of UNPD standard model life tables does not dictate the level of mortality since alpha is determined from the empirical conditional 
survival probability.

Furthermore, the use of UNPD mortality estimates for comparison with the study estimates is meant to be indicative and not to imply that UNPD mortality estimates have no limitations, which arise from the quality of data, assumptions and methods used to derive them.

The impact of replacing the standard model life tables derived from UNPD population estimates and projections data with Brass' General standard model life table (Brass, Coale, Demeny et al., 1968), which does not allow for the changing impact of AIDS on mortality over time, was investigated. A comparison of adult mortality rates obtained from the two types of standard model life tables indicated that mortality rates translated by using Brass's General Standard (not shown here) are lower than those estimated by using the model life tables derived from the UNPD population estimates and projections. This indicates that utilising standard model life tables that account for HIV and AIDS produces higher estimates of adult mortality, ${ }_{45} q_{15}$, that reflect the impact of the epidemic on mortality than the Brass standard model life table. This is the unique feature of this study to show the impact of HIV on mortality as it changes over the course of the epidemic by utilising standard model life tables that account for the HIV and AIDS.

This study has made use of underutilised data from the Living Conditions Monitoring Surveys to estimate the levels and trends of adult mortality. The data from the Living Conditions Monitoring Surveys posed a lot of challenges as their quality is not as good as those of the Demographic and Health Surveys. This meant a lot of time was spent interrogating and adjusting the data for it to be usable. It is encouraging that results obtained from applying the orphanhood method to 2002/3, 2004 and 2006 LCMS surveys were consistent with those derived from the 200I/ 2 , and $200 \square$ ZDHS surveys.

The study found that adult mortality rates estimated using the orphanhood method applied to LCMS and ZDHS surveys were consistent with those of the UNPD for the early to mid-1980s period in a number of cases. Around the 2000s, however, these estimates were lower, possibly due to the problem of adoption effect.

To ensure that estimates of the study are comparable to those of other studies. Orphanhood mortality estimates by Timaeus and Jasseh (2004) were first reproduced and used as a base to produce mortality estimates from ZDHS and LCMS survey orphanhood data. The 1992 and 1996 ZDHS surveys orphanhood mortality estimates are the same as those of Timaeus and Jasseh (2004). This study extended these estimates to cover the $2001 / 2$ and 200 $\square$ ZDHS surveys, in addition, to deriving estimates obtained using orphanhood data from the LCMS surveys.

Adult mortality estimates derived from surveys in this study using data on orphanhood are merely indicative of the level and possibly underestimate the actual level. It is, therefore, recommended that, to obtain more plausible estimates of adult mortality in Zambia using robust methods, census undertaking should collect information on deaths in households in the past year. From the 
study, the level of adult mortality among middle-aged men and women is high in Zambia, it is therefore, recommended that health interventions should be targeted at adult health, and in addition, development programmes should address the socio-economic consequences of high mortality of adults.

\section{References}

Ainsworth, M., K. Beegle and G. Koda. 2005. "The impact of adult mortality and parental deaths on primary schooling in north-western Tanzania", Journal of Development Studies 4 I (3):4 I 2-439.

Baggaley, R., P. Godfrey-Faussett, R. Msiska et al., 1994. "Impact of HIV infection on Zambian Business", British Medical Journal (309): I5491550.

Blacker, J. G. C. 19प. "Estimation of Adult Mortality in Africa from data on Orphanhood", Population Studies 3 I (I): 10-128.

Bradshaw, D. and I. M. Timaeus. 2006. "Levels and Trends in Adult Mortality," in Jamison, D.T., R. G. A. Feachem, M.W. Makgoba, et al., (eds). Disease and Mortality in SubSaharan Africa. Washington, D.C., USA: The International Bank for Reconstruction and Development/ The World Bank, pp.

Brass, W., J.A. Coale, P. Demeny et al., 1968. The Demography of Tropical Africa. Princeton, New Jersey: Princeton University Press.

Brass, W. and K. Hill. 19๑3. "Estimating Adult Mortality from Orphanhood," Paper presented at International Population Conference, Liege, 19 3. Liege. International Union for the Scientific Study of Population. Vol.
3:III-123.

Central Statistical Office, Central Board of Health and ORC Macro. 199 Zambia Demographic and Health Survey 1996. Calverton, Maryland, USA: Central Statistical Office, Central Board of Health, ORC Macro.

Central Statistical Office, Central Board of Health and ORC Macro. 2003. Zambia Demographic and Health Survey 200I-2002. Calverton, Maryland, USA: Central Statistical Office, Central Board of Health, ORC Macro.

Central Statistical Office, Ministry of Health, Tropical Diseases Research Centre et al., 2009. Zambia Demographic and Health Survey 2007. Calverton, Maryland, USA: Central Statistical Office and Macro International.

Central Statistical Office and World Bank. Unpublished. Living Conditions Monitoring Surveys 1996, 1998, 2002/3, 2004 \& 2006 CD-ROM Raw Data. Lusaka: Central Statistical Office.

Chapoto, A. and T.S. Jayne. 2005. Characteristics of Individuals Afflicted by AIDS-Related Mortality in Zambia. Working Paper No. 14. Lusaka, Zambia: Food Security Research Project.

Chisumpa, V.H. 20I0. "Estimation of the level and trend of adult mortality in Zambia." Unpublished dissertation, Cape Town: University of Cape Town.

Coale, A.J., P. Demeny and B. Vaughan. 1983. Regional Model Lite Tables and Stable Populations. New York: Academic Press.

Dorrington, R., I. M. Timaeus and S. 
Gregson. 200[. "Adult mortality in Southern Africa using deaths by household: some methodological issues and results," Paper presented at 200 Union for African Population Studies Conference. Arusha, Tanzania

Feeney, G. 200I. "The Impact of HIV/ AIDS on Adult Mortality in Zimbabwe", Population and Development Review 27(4): $\square \mathrm{I}-\square 80$.

Hill, K. 200I. Methods for Measuring Adult Mortality in Developing Countries: A Comparative Review. The Global Burden of Disease 2000 in Aging Populations. Research Paper No.01.13.

Cambridge, Massachusetts: Harvard Burden of Disease Unit. Centre for Population and Development Studies.

Macro International Inc. 2009. HIV prevalence remains high in Zambia, knowledge of prevention and HIV testing lagging. http:// www.measuredhs.com/prl/ post.cfm?id=47E889C3-5056-9F36DC59B0184AOBDDBA. Accessed: March 28,2009

Ministry of Health and Central Board of Health. 2005. Zambia Antenatal Clinic Sentinel Surveillance Report, 1994-2004. Lusaka: Ministry of Health, Central Board of Health.

Ngom, P. and S.J. Clark. 2003. "Adult Mortality in the Era of HIV/AIDS: Sub-Saharan Africa," Paper presented at Training Workshop on HIV/AIDS and Adult Mortality in Developing Countries, 8-13 September,2003. New York. Department of Economic and Social Affairs. Population Division. United Nations. UN/POP/MORT/2003/3 http://www.un.org/esa/population/ publications/adultmort/

CLARK_Paper3.pdf Accessed: 10th October, 200].

Noumbissi, Amadou, Ayaga.A Bawah and Tukufu Zuberi. 2005. "Parental Survival and Residential Patterns," in Zuberi, Tukufu, Amson Sibanda and Eric.O Udjo (eds). The Demography of South Africa. New York: M.E. Sharpe, Inc, pp. 160-180.

Population Council. 1998. "The United Nations on the impact of HIV/AIDS on adult mortality in Sub-Saharan Africa", Population and Development Review 24(3):655-658.

Preston, S.H., P. Heuveline and M. Guillot. 200I. Demography: measuring and modelling population processes. Oxford: Blackwell Publishers.

Timaeus, I. M. 199I. "Measurement of Adult Mortality in Less Developed Countries: A Comparative Review", Population Index 57(4):552-568.

Timaeus, I. M. 1992. "Estimation of adult mortality from paternal orphanhood: A reassessment and a new approach", Population Bulletin of the United Nations (33):4[-63.

Timaeus, I. M. and M. Jasseh. 2004. "Adult mortality in sub-Saharan Africa: Evidence from Demographic and Health Surveys", Demography 4 I (4): $\square 5 \square-\square 2$.

Timaeus, I. M. and A.J. Nunn. 1997. "Measurement of Adult Mortality in Populations Affected by AIDS: An Assessment of Orphanhood Method", Health Transition Review 7(suppl 2):S23-S43.

UNAIDS/WHO. 2009. 2008 Report on the global AIDS epidemic. UNAIDS.

United Nations. 2002. Methods for Estimating Adult Mortality. New 
York: Department of Economic and Social Affairs. Population Division ESA/P/WP.I $\square 5$.

United Nations. 2006. United Nations Expert Group Meeting on Current Issues in the Estimation of Adult Mortality: Report of the meeting of 26-27 October,2006. New York: Department of Economic and Social Affairs. Population Division.

United Nations Department of Economic and Social Affairs Population Division. 2009. World Population Prospects: The 2008 Revision, CD-ROM Edition - Extended
Dataset in Excel and ASCll formats. (United Nations publication, Sales No. E.09. XII.6).

World Health Organization (WHO). 2009. World Health Statistics 2009. Mortality and burden of disease: Table I. Geneva: World Health Organization.

Zlotnik, H. and K. Hill. 198I. "The Use of Hypothetical Cohorts in Estimating Demographic Parameters under Conditions of Changing Fertility and Mortality", Demography 18(I): 103-122. 